\title{
Nonlinear Dynamic Analysis of an Orthotropic Composite Rotor Blade
}

\author{
Ming-Hung Hsu \\ Department of Electronic Engineering, National Penghu Institute of Technology, No. 300, Liu-Ho Rd., Makung City, \\ Penghu Hsien, Taiwan 880, R.O.C., hsu@npit.edu.tw
}

Follow this and additional works at: https://jmstt.ntou.edu.tw/journal

Part of the Electrical and Computer Engineering Commons

\section{Recommended Citation}

Hsu, Ming-Hung (2004) "Nonlinear Dynamic Analysis of an Orthotropic Composite Rotor Blade," Journal of Marine Science and Technology. Vol. 12: Iss. 4, Article 3.

DOI: $10.51400 / 2709-6998.2244$

Available at: https://jmstt.ntou.edu.tw/journal/vol12/iss4/3

This Research Article is brought to you for free and open access by Journal of Marine Science and Technology. It has been accepted for inclusion in Journal of Marine Science and Technology by an authorized editor of Journal of Marine Science and Technology. 


\title{
NONLINEAR DYNAMIC ANALYSIS OF AN ORTHOTROPIC COMPOSITE ROTOR BLADE
}

\author{
Ming-Hung Hsu
}

Key words: orthotropic composite rotor blade, differential quadrature method, vibration, numerical method.

\begin{abstract}
This work presents the nonlinear dynamic analysis of orthotropic composite rotor blade using differential quadrature method (DQM). It can be found that the same efficient and procedure of DQM for both uniform composite beam and pre-twisted non-uniform composite beam. In this approach, only nine sample points are needed to achieve convergence. Dynamic responses of orthotropic composite rotor blade with various rotor rotation speeds are determined. Both linear and nonlinear dynamic responses have been obtained in order to study the significance of the nonlinear effect. The transient responses of the derived systems are calculated by using Newmark method. The bending-torsion coupled beam model is used to characterize the composite rotor blade. Kelvin-Voigt internal and linear external damping coefficients are employed and determined for the orthotropic composite rotor blade. The DQM is used to transform the partial differential equations of a composite rotor blade into a discrete eigenvalue problem. In this study, the effects of the fiber orientation, internal damping, external damping, pre-twisted angle and the rotation speed on the dynamic behavior for an orthotropic composite beam are investigated. The effect of the number of sample points on the accuracy of the calculated natural frequencies is also discussed. The integrity and computational efficiency of the DQM in this problem will be derived in this paper.
\end{abstract}

\section{INTRODUCTION}

In the design of rotor blade, fiber reinforced composites have been used. Fiber reinforced composite material in blade applications has stimulated a considerable amount of study. Sivaneri and Chopra [24] solved the nonlinear trim equation of a flap-lag-torsion blade using the finite element method. Crespo Da Silva [13] analyzed the problem of determining the equilibrium soultion and the eigenvalues of a helicopter rotor blade in hover in a mathematically exact manner. Firedmann et al. [14] presented the vibration reduction

Paper Submitted 03/1 1/04, Accepted 08/20/04. Author for Correspondence: Ming-Hung Hsu. E-mail: hsu@npit.edu.tw.

*Department of Electronic Engineering, National Penghu Institute of Technology, No. 300, Liu-Ho Rd., Makung City, Penghu Hsien, Taiwan 880, R.O.C. studies conducted on a servo flap configuration, a plain flap configuration and a dual servo flap using independent control. Wang and Peters [27] studied the interaction of wake dynamics and blade flapping dynamics through the mode shapes and eigenvalues of coupled modes' continuous vibrations. Ruzicka and Hodges [21] described the derivation of a mixed element and the element's effectiveness in modal reduction for a articulated blade model. Schultz and Tsai [22] presented data concerning the dynamic material behavior in a glassfilament reinforced epoxy composite. Abarcar and Cunniff [1] presented the fiber orientation effect on the vibration mode in cantilever beams made of unidirectional fiber reinforced composite materials. Shiau et al. [23] investigated the vibration and optimum design of a rotating laminated blade subject to constraints on the dynamic behavior. Rand and Barkai [20] presented a nonlinear formulation for the structural behavior of initially twisted solid and thin walled composite blades. Lekhnitskii [16] solved the static response of an orthotropic composite beam subjected to the simultaneous action of an applied bending moment and an applied torque. Thomas [25] developed a variation principle for a non-conservatively loaded cantilever beam with Kelvin-Voigt internal and linear external damping. Chen and Chen [9, 10] and Chen and Shen [11] applied the finite element model to study the dynamic stability aspects of a cracked orthotropic beam and investigated the mean square response and reliability of a rotating composite blade with external and internal damping.

The dynamic characteristics of composite material structure are important in high-speed rotor blade designs. In this work, the differential quadrature method (DQM) was employed to formulate the eigenvalue problem of an orthotropic composite rotor blade in matrix form. The effects of the external and internal damping on the natural frequencies of the orthotropic composite rotor blade were also considered in the formulation. The integrity and computational efficiency of the DQM in this problem will be demonstrated through a series of case studies. This paper shows the detailed implementation of DQM in the nonlinear vibration analysis of a 
composite rotor blade with internal and external damping. As noted in a number of papers, the DQM is a very efficient method for different structural analysis. The efficiency and the accuracy of Rayleigh-Ritz method are dependent on the number and the accuracy of the selected comparison functions. However, there is no this kind difficulty to selected the appropriate comparison functions in the DQ technology. To the author's knowledge, very few published papers in the literature have presented the nonlinear vibration analysis of an orthotropic composite rotor blade using the DQM.

\section{FORMATION OF THE DYNAMIC PROBLEM}

Geometry of an orthotropic composite rotor blade structure is showed in Figure 1. The composite rotor blade is attached to a hub. Axes 1, 2, and 3 are the local axes and axes $x, y$ and $z$ are the global blade axes. $\theta_{f}$ is the fiber orientation. Consider the orthotropic composite beam subjected to a bending moment $M_{B}(z, t)$ and a torsion moment $M_{T}(z, t)$ simultaneously. The bending and torsion moments can then be expressed as [16]

$$
\begin{aligned}
& M_{B}=\frac{E_{z z} I_{x x}}{\eta}\left(\frac{\partial^{2} v}{\partial z^{2}}+\frac{C_{t}}{C_{m t}} \frac{\partial \phi}{\partial z}\right) \\
& M_{T}=\frac{C_{t}}{\eta}\left(\frac{E_{z z} I_{x x}}{C_{m t}} \frac{\partial^{2} v}{\partial z^{2}}+\frac{\partial \phi}{\partial z}\right)
\end{aligned}
$$

where $v(z, t)$ and $\phi(z, t)$ represent the displacement of the rotor blade in axis and the twist angle of the rotor blade in $z$ axis, respectively. For a composite rotor blade, the

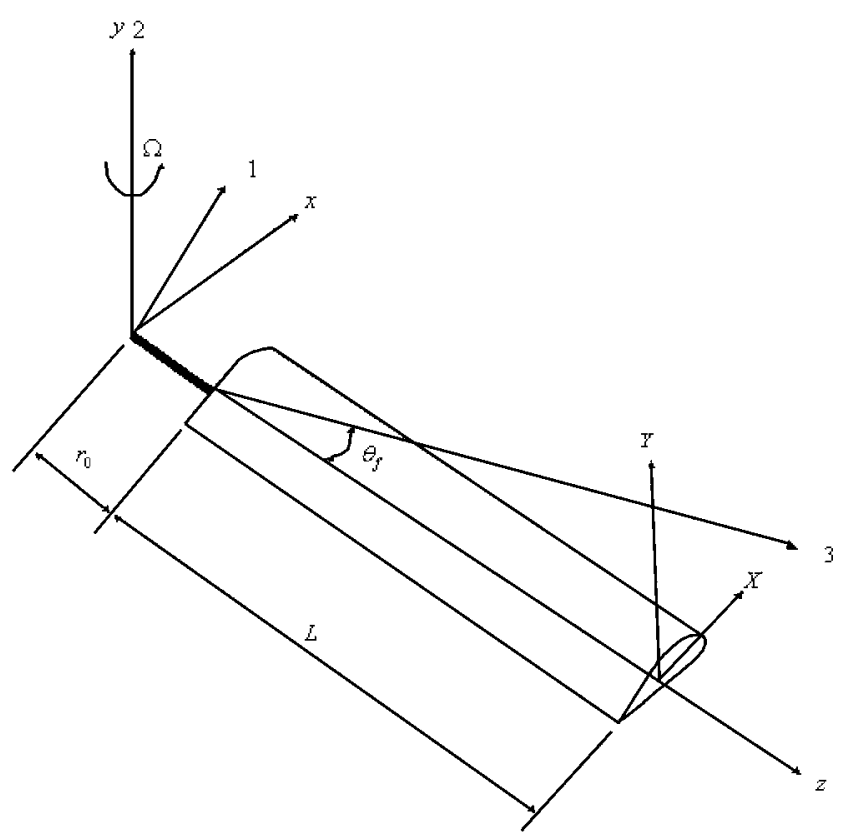

Fig. 1. Geometry of a composite rotor blade. parameters used in the above equations are defined as

$$
\begin{aligned}
& I_{x x}=I_{X X} \cos ^{2}\left(\frac{z}{L} \theta_{t}\right)+I_{Y Y} \sin ^{2}\left(\frac{z}{L} \theta_{t}\right) \\
& C_{t}(z)= \\
& \frac{b h^{3}}{3} \frac{1-0.63 \frac{h}{b}}{\frac{1}{G_{x z}}-0.63\left(\left(\left(\frac{\sin ^{2} \theta_{f}}{E_{11}}-\frac{\cos ^{2} \theta_{f}}{E_{33}}\right) \sin 2 \theta_{f}+\frac{1}{4}\left(\frac{1}{G_{13}}-\frac{2 v_{31}}{E_{33}}\right) \sin 4 \theta_{f}\right)^{2} E_{z z} \frac{h}{b}\right)}
\end{aligned}
$$

$$
\begin{aligned}
& \eta=1-\frac{E_{z z} I_{x x} C_{t}}{C_{m t}^{2}} \\
& C_{m t}=\frac{2 I_{x x}}{\left(\frac{\sin ^{2} \theta_{f}}{E_{11}}-\frac{\cos ^{2} \theta_{f}}{E_{33}}\right) \sin 2 \theta_{f}+\frac{1}{4}\left(\frac{1}{G_{13}}-\frac{2 v_{31}}{E_{33}}\right) \sin 4 \theta_{f}}
\end{aligned}
$$

$$
\begin{aligned}
& E_{z z}=\frac{1}{\frac{\sin ^{4} \theta_{f}}{E_{11}}+\frac{\cos ^{4} \theta_{f}}{E_{33}}+\frac{1}{4}\left(\frac{1}{G_{13}}-\frac{2 v_{31}}{E_{33}}\right) \sin ^{2} \theta_{f}} \\
& G_{x z}=\frac{1}{\left(\frac{1}{E_{11}}+\frac{1}{E_{33}}+\frac{2 v_{31}}{E_{33}}\right) \sin ^{2} \theta_{f}+\frac{\cos ^{2} \theta_{f}}{G_{13}}}
\end{aligned}
$$

where $b$ is the breath of the rotor blade, $h$ is the thickness of the rotor blade, $v$ is the displacement of the rotor blade in $y$ axis, $E_{11}$ and $E_{33}$ are Young's modulus in 1 and 3 axes, $v_{31}$ is the Poisson's ratio, $G_{13}, G_{12}$ and $G_{23}$ are shear modulus in 1-3, 1-2 and 2-3 planes, $I_{x x}, I_{X X}$ and $I_{Y Y}$ are the moments of area, $\theta_{t}$ is the twist angle of the rotor blade. The kinetic energy of the rotating orthotropic composite rotor blade can be derived as

$$
\begin{aligned}
T & =\frac{1}{2} \int_{0}^{L} \rho A\left(\frac{\partial v}{\partial t}\right)^{2} d z+\frac{1}{2} \int_{0}^{L} \rho A\left(\frac{\partial w}{\partial t}\right)^{2} d z \\
& +\frac{1}{2} \int_{0}^{L} \rho J_{z}\left(\frac{\partial \phi}{\partial t}\right)^{2} d z+\frac{1}{2} \rho A \Omega^{2}\left(r_{0}+z+w\right)^{2}
\end{aligned}
$$
blade is

The corresponding strain energy of the rotating

$$
\begin{aligned}
U & =\frac{1}{2} \int_{0}^{L} M_{B}\left(\frac{\partial^{2} v}{\partial z^{2}}\right) d z+\frac{1}{2} \int_{0}^{L} M_{T}\left(\frac{\partial \phi}{\partial z}\right) d z \\
& +\frac{1}{2} \int_{0}^{L} E_{z z} A\left[\frac{\partial w}{\partial z}+\frac{1}{2}\left(\frac{\partial v}{\partial z}\right)^{2}\right]^{2} d z
\end{aligned}
$$

Substituting Eqs. (1) and (2) into Eq. (10), it leads 


$$
\begin{aligned}
U & =\frac{1}{2} \int_{0}^{L} \frac{E_{z z} I_{x x}}{\eta}\left(\frac{\partial^{2} v}{\partial z^{2}}\right) d z+\int_{0}^{L} \frac{C_{t} E_{z z} I_{x x}}{\eta C_{m t}}\left(\frac{\partial^{2} v}{\partial z^{2}}\right)\left(\frac{\partial \phi}{\partial z}\right) d z \\
& +\frac{1}{2} \int_{0}^{L} \frac{C_{t}}{\eta}\left(\frac{\partial \phi}{\partial z}\right)^{2} d z+\frac{1}{2} \int_{0}^{L} E_{z z} A\left[\frac{\partial w}{\partial z}+\frac{1}{2}\left(\frac{\partial v}{\partial z}\right)^{2}\right]^{2} d z
\end{aligned}
$$

With considering the internal and external damping effects in the orthotropic composite blade, the virtual work $\delta W$ in the blade can be derived as

$$
\begin{aligned}
\delta W & =-\int_{0}^{L} c_{0} \frac{\partial v}{\partial t} \delta v d z-\int_{0}^{L} c_{\phi} \frac{\partial \phi}{\partial t} \delta \phi d z-\int_{0}^{L} c_{w} \frac{\partial w}{\partial t} \delta \phi d z \\
& -\int_{0}^{L} \frac{\partial^{2}}{\partial z^{2}}\left(\frac{E_{z z} I_{x x}}{\eta}\right) c_{1} \frac{\partial^{3} v}{\partial t \partial z^{2}} \delta v d z \\
& -2 \int_{0}^{L} \frac{\partial}{\partial z}\left(\frac{E_{z z} I_{x x}}{\eta}\right) c_{1} \frac{\partial^{4} v}{\partial t \partial z^{4}} \delta v d z \\
& -\int_{0}^{L} \frac{E_{z z} I_{x x}}{\eta} c_{1} \frac{\partial^{5} v}{\partial t \partial z^{4}} \delta v d z \\
& +\int_{0}^{L} F_{v} \delta v d z+\int_{0}^{L} F_{\phi} \delta \phi d z
\end{aligned}
$$

with

$$
\begin{aligned}
& J_{z}=\frac{C_{t}}{G_{x y}} \\
& G_{x y}=\frac{1}{\frac{\sin ^{2} \theta_{f}}{G_{23}}+\frac{\cos ^{2} \theta_{f}}{G_{12}}}
\end{aligned}
$$

where $w$ is the displacement of the rotor blade in the $z$ axis direction, $A$ is the section area of the rotor blade, $\Omega$ is the rotation speed of the rotor speed, $J_{z}$ is the polar moment of inertia, $\rho$ is the density of the material and $r_{o}$ is the length of hub. $F_{v}$ is the lift acting on the rotor blade. $F_{\phi}$ represents the moment acting on the rotor blade. $c_{1}$ is the internal damping coefficient of the composite rotor blade. $c_{o}, c_{\phi}$ and $c_{w}$ are the external damping coefficient of the composite rotor blade, respectively. Substituting Eqs. (9), (11) and (12) into Hamilton equation

$$
\int_{t_{1}}^{t_{2}}(\delta t-\delta U+\delta W) d t=0
$$

The differential equations governing the nonlinear flexural-torsion dynamics of composite rotor blade are

$$
\begin{aligned}
& \rho A \frac{\partial^{2} v}{\partial t^{2}}+c_{0} \frac{\partial v}{\partial t}+\frac{\partial^{2}}{\partial z^{2}}\left(\frac{E_{z z} I_{x x}}{\eta}\right) c_{1} \frac{\partial^{3} v}{\partial t \partial z^{2}} \\
& +2 \frac{\partial}{\partial z}\left(\frac{E_{z z} I_{x x}}{\eta}\right) c_{1} \frac{\partial^{4} v}{\partial t \partial z^{3}}+\frac{E_{z z} I_{x x}}{\eta} c_{1} \frac{\partial^{5} v}{\partial t \partial z^{4}}
\end{aligned}
$$

$$
\begin{aligned}
& +\frac{\partial^{2}}{\partial z^{2}}\left(\frac{E_{z z} I_{x x}}{\eta}\right) \frac{\partial^{2} v}{\partial z^{2}}+2 \frac{\partial}{\partial z}\left(\frac{E_{z z} I_{x x}}{\eta}\right) \frac{\partial^{3} v}{\partial z^{3}} \\
& +\frac{E_{z z} I_{x x}}{\eta} \frac{\partial^{4} v}{\partial z^{4}}+\frac{\partial^{2}}{\partial z^{2}}\left(\frac{C_{t} E_{z z} I_{x x}}{\eta C_{m t}}\right) \frac{\partial \phi}{\partial z} \\
& +2 \frac{\partial}{\partial z}\left(\frac{C_{t} E_{z z} I_{x x}}{\eta C_{m t}}\right) \frac{\partial^{2} \phi}{\partial z^{2}}+\frac{C_{t} E_{z z} I_{x x}}{\eta C_{m t}} \frac{\partial^{3} \phi}{\partial z^{3}} \\
& -\frac{\partial}{\partial z}\left(E_{z z^{A}} A\left[\frac{\partial w}{\partial z}+\frac{1}{2}\left(\frac{\partial v}{\partial z}\right)^{2}\right]\left(\frac{\partial v}{\partial z}\right)\right. \\
& -E_{z z^{\prime}} A\left[\frac{\partial^{2} w}{\partial z^{2}}+\left(\frac{\partial v}{\partial z}\right)\left(\frac{\partial^{2} v}{\partial z^{2}}\right)\right]\left(\frac{\partial v}{\partial z}\right) \\
& -E_{z z} A\left[\frac{\partial w}{\partial z}+\frac{1}{2}\left(\frac{\partial v}{\partial z}\right)^{2}\right]\left(\frac{\partial^{2} v}{\partial z^{2}}\right)-F_{v}=0 \\
& \rho A \frac{\partial^{2} w}{\partial t^{2}}+c_{w} \frac{\partial w}{\partial t}-\frac{\partial}{\partial z}\left(E_{z z^{2}} A\right)\left[\frac{\partial w}{\partial z}+\frac{1}{2}\left(\frac{\partial v}{\partial z}\right)^{2}\right] \\
& \rho J_{z}(z) \frac{\partial^{2} \phi}{\partial t^{2}}+C_{\phi} \frac{\partial \phi}{\partial t}-\frac{\partial}{\partial z}\left(\frac{C_{t} E_{z z} I_{x x}}{\eta C_{m t}}\right) \frac{\partial^{2} v}{\partial z^{2}} \\
& -\frac{C_{t} E_{z z} I_{x x}}{\eta C_{m t}} \frac{\partial^{3} v}{\partial z^{3}}-\frac{\partial}{\partial z}\left(\frac{C_{t}}{\eta}\right) \frac{\partial \phi}{\partial t}-\frac{C_{t}}{\eta} \frac{\partial^{2} \phi}{\partial z^{2}}-F_{\phi}=0 \\
& \left.-\left(\frac{\partial v}{\partial z}\right)\left(\frac{\partial^{2} v}{\partial z^{2}}\right)\right]-\rho A \Omega^{2}\left(r_{0}+z+w\right)=0
\end{aligned}
$$

The corresponding boundary conditions are

$$
\begin{aligned}
& v(0, t)=0 \\
& \frac{\partial v(0, t)}{\partial z}=0 \\
& \frac{E_{z z} I_{x x}}{\eta} \frac{\partial^{2} v(L, t)}{\partial z^{2}}+\frac{C_{t} E_{z z} I_{x x}}{\eta C_{m t}} \frac{\partial \phi(L, t)}{\partial z}=0 \\
& \frac{\partial}{\partial z}\left[\frac{E_{z z} I_{x x}}{\eta} \frac{\partial^{2} v(L, t)}{\partial z^{2}}\right]+\frac{\partial}{\partial z}\left[\frac{C_{t} E_{z z} I_{x x}}{\eta C_{m t}} \frac{\partial \phi(L, t)}{\partial z}\right]=0
\end{aligned}
$$

$\phi(0, t)=0$

$\frac{C_{t}}{\eta}\left[\frac{E_{z z} I_{x x}}{C_{m t}} \frac{\partial^{2} v(L, t)}{\partial z}+\frac{\partial \phi(L, t)}{\partial z}\right]=0$

$w(0, t)=0$ 


$$
E_{z z^{A}}\left\{\frac{\partial w(L, t)}{\partial z}+\frac{1}{2}\left[\frac{\partial v(L, t)}{\partial z}\right]^{2}\right\}=0
$$

\section{DIFFERENTIAL QUADRATURE METHOD}

The DQM was introduced by Bellman and Casti [2] and Bellman et al. [3] in the early 1970s. DQM has been extensively used to solve a variety of problems in different fields of science and engineering $[4,5,6,7,8$, 17]. DQM has been shown to be a powerful contender in solving initial and boundary value problems and thus has become an alternative to the existing methods. In the DQ technology, the derivative of a function at a given point can be approximated as a weighted linear sum of the functional values at all of the sample points in the domain of that variable. Using this approximation, the differential equation is then reduced into a set of algebraic equations. The number of equations is dependent upon the selected number of sample points within the domain. Suppose that there are $N$ sample points in the domain. For a function $f(z), \mathrm{DQM}$ approximation for the $m^{\text {th }}$ order derivative at the sample point $z_{i}$ is given by

$$
\frac{\partial^{m}}{\partial z^{m}}\left\{\begin{array}{c}
f\left(z_{1}, t\right) \\
f\left(z_{2}, t\right) \\
\vdots \\
f\left(z_{N}, t\right)
\end{array}\right\} \cong\left[D_{i j}^{(m)}\right]\left\{\begin{array}{c}
f\left(z_{1}, t\right) \\
f\left(z_{2}, t\right) \\
\vdots \\
f\left(z_{N}, t\right)
\end{array}\right\}
$$

$$
\text { for } i, j=1,2, \ldots, N
$$

where $f\left(z_{i}\right)$ is the functional value at the sample point $z_{i}$, and $D_{i j}^{(m)}$ are the DQ coefficients of the $m^{\text {th }}$ order differentiation attached to these functional values. In order to determine the DQ coefficients $D_{i j}^{(m)}$ of first order derivatives can be obtained from the following equation [18, 19],

$$
D_{i j}^{(1)}=\frac{1}{z_{j}-z_{i}} \prod_{\substack{k \neq i \\ k \neq j \\ k=1}}^{N} \frac{z_{i}-z_{k}}{z_{j}-z_{k}}
$$

for $i=1,2, \ldots, N$ and $j=1,2, \ldots, N$

$$
D_{i j}^{(1)}=\sum_{k \neq i}^{N} \frac{1}{z_{i}-z}
$$

$$
\text { for } i=1,2, \ldots, N
$$

Once the sample points, i.e. $z_{i}$, for $i=1,2, \ldots, N$, are selected, the coefficients of the DQ matrix can be obtained from Eqs. (28) and (29). Higher-order derivatives of DQ coefficients can be obtained by matrix multiplication, which are

$$
\begin{aligned}
& D_{i j}^{(2)}=\sum_{k=1}^{N} D_{i k}^{(1)} D_{k j}^{(1)} \text { for } i=1,2, \ldots, N \\
& D_{i j}^{(3)}=\sum_{k=1}^{N} D_{i k}^{(1)} D_{k j}^{(2)} \text { for } i=1,2, \ldots, N \\
& D_{i j}^{(4)}=\sum_{k=1}^{N} D_{i k}^{(1)} D_{k j}^{(3)} \text { for } i=1,2, \ldots, N
\end{aligned}
$$

The unequally spaced inner points of each blade using the Chebyshev-Gauss-Lobatto distribution [5] in the present computation are distributed as

$$
z_{i}=\frac{1}{2}\left[1-\cos \frac{(i-1)}{N-1}\right] \text { for } i=1,2, \ldots, N
$$

\section{NUMERICAL FORMATIONS}

By employing the DQ technology, Eq. (27) is substituted into Eqs. (16) to (26). The equations of motion for the orthotropic composite blade can be rearranged in matrix form as

$$
[M]\left\{\frac{\partial^{2} y}{\partial t^{2}}\right\}+[C]\left\{\frac{\partial y}{\partial t}\right\}+[K]\{y\}-[F\}=0
$$

where

$$
\left\{\begin{array}{c}
y\left(z_{1}, t\right) \\
y\left(z_{2}, t\right) \\
\vdots \\
y\left(z_{N}, t\right) \\
y\left(z_{N+1}, t\right) \\
y\left(z_{N+2}, t\right) \\
\vdots \\
y\left(z_{2 N}, t\right) \\
y\left(z_{2 N+1}, t\right) \\
y\left(z_{2 N+2}, t\right) \\
\vdots \\
y\left(z_{3 N}, t\right)
\end{array}\right\}=\left\{\begin{array}{c}
v\left(z_{1}, t\right) \\
v\left(z_{2}, t\right) \\
\vdots \\
v\left(z_{N}, t\right) \\
\phi\left(z_{1}, t\right) \\
\phi\left(z_{2}, t\right) \\
\vdots \\
\phi\left(z_{N}, t\right) \\
w\left(z_{1}, t\right) \\
w\left(z_{2}, t\right) \\
\vdots \\
w\left(z_{N}, t\right)
\end{array}\right\}
$$

The elements in the mass matrix are

$$
\begin{aligned}
& M_{i i}=\rho A \text { for } i=3,4, \ldots, N-2 \\
& M_{i i}=\rho J_{z} \text { for } i=N+2, N+3, \ldots, 2 N-1 \\
& M_{i i}=\rho A \text { for } i=2 N+2,2 N+3, \ldots, 3 N-1 \\
& M_{i i}=0 \text { for } i=1,2, N-1, N, N+1,2 N, 2 N+1,3 N
\end{aligned}
$$

$M_{i j}=0$ for $i \neq j, i=1,2, \ldots, 3 N$ and $j=1,2, \ldots, 3 N$ 
The elements in the damping matrix are

$$
\begin{aligned}
C_{i i} & =c_{o}+c_{1} \frac{\partial^{2}}{\partial z^{2}}\left(\frac{E_{z z} I_{x x}}{\eta}\right) D_{i i}^{(2)}+2 c_{1} \frac{\partial}{\partial z}\left(\frac{E_{z z} I_{x x}}{\eta}\right) D_{i i}^{(3)} \\
& +\frac{E_{z z} I_{x x} C_{1}}{\eta} D_{i i}^{(4)} \text { for } i=3,4, \ldots, N-2 \\
C_{i j} & =c_{1} \frac{\partial^{2}}{\partial z^{2}}\left(\frac{E_{z z} I_{x x}}{\eta}\right) D_{i j}^{(2)}+2 c_{1} \frac{\partial}{\partial z}\left(\frac{E_{z z} I_{x x}}{\eta}\right) D_{i j}^{(3)} \\
& +c_{1} \frac{E_{z z} I_{x x}}{\eta} D_{i j}^{(4)}
\end{aligned}
$$

for $i \neq j, i=3,4, \ldots, N-2$ and $j=1,2, \ldots, N$

$C_{i i}=c_{\phi}$ for $i=N+2, N+3, \ldots, 2 N-1$

$C_{i i}=c_{w}$ for $i=2 N+2,2 N+3, \ldots, 3 N-1$

$C_{i i}=0$ for $i=1,2, N-1, N, N+1,2 N, 2 N+1,3 N$

$C_{i j}=0$ for $i=1,2, \ldots, N$ and $j=N+1, N+2, \ldots, 3 N$

$C_{i j}=0$ for $i \neq j, i=N+1, N+2, \ldots, 3 N$

and $j=1,2, \ldots, 3 N$

The elements in the stiffness matrix are

$$
\begin{aligned}
K_{i j} & =\frac{\partial^{2}}{\partial z^{2}}\left(\frac{E_{z z} I_{x x}}{\eta}\right) D_{i j}^{(2)}+2 c \frac{\partial}{\partial z}\left(\frac{E_{z z} I_{x x}}{\eta}\right) D_{i j}^{(3)} \\
& +\frac{E_{z z} I_{x x}}{\eta} D_{i j}^{(4)}+\frac{\partial}{\partial z}\left(E_{z z^{A}} A\right)\left[\frac{\partial w}{\partial z}+\frac{1}{2}\left(\frac{\partial v}{\partial z}\right)^{2}\right] D_{i j}^{(1)} \\
& +\left(E_{z z^{A}} A\right)\left[\frac{\partial^{2} w}{\partial z^{2}}+\left(\frac{\partial v}{\partial z}\right)\left(\frac{\partial^{2} w}{\partial z^{2}}\right)\right] D_{i j}^{(1)} \\
& +\left(E_{z z^{A}} A\right)\left[\frac{\partial w}{\partial z}+\frac{1}{2}\left(\frac{\partial v}{\partial z}\right)^{2}\right] D_{i j}^{(2)}=0
\end{aligned}
$$

for $i=3,4, \ldots, N-2$ and $j=1,2, \ldots, N$

$K_{i j}=\frac{\partial^{2}}{\partial z^{2}}\left(\frac{C_{t} E_{z z} I_{x x}}{\eta C_{m t}}\right) D_{i, j-N}^{(1)}+2 \frac{\partial}{\partial z}\left(\frac{C_{t} E_{z z} I_{x x}}{\eta C_{m t}}\right) D_{i, j-N}^{(2)}$

$$
\begin{aligned}
& \quad \text { and } j=N+1, N+2, \ldots, 2 N \\
& K_{i j}=0 \text { for } i=3,4, \ldots, N-2 \\
& \text { and } j=2 N+1,2 N+2, \ldots, 3 N \\
& K_{i j}=0 \text { for } i=1,2, N-1, N \\
& \text { and } j=1,2, \ldots, 3 N
\end{aligned}
$$$$
+\frac{C_{t} E_{z z} I_{x x}}{\eta C_{m t}} D_{i, j-N}^{\phi(3)} \text { for } i=3,4, \ldots, N-2
$$

$K_{i j}=-\frac{\partial}{\partial z}\left(\frac{C_{t} E_{z z} I_{x x}}{\eta C_{m t}}\right) D_{i-N, j}^{(2)}-\frac{C_{t} E_{z z} I_{x x}}{\eta C_{m t}} D_{i-N, j}^{(3)}$

for $i=N+2, N+3, \ldots, 2 N-1$ and $j=1,2, \ldots, N$

$K_{i j}=-\frac{\partial}{\partial z}\left(\frac{C_{t}}{\eta}\right) D_{i-N, j-N}^{(1)}-\frac{C_{t}}{\eta} D_{i-N, j-N}^{(2)}$

for $i=N+2, N+3, \ldots, 2 N-1$

and $j=N+1, N+2, \ldots, 2 N$

$K_{i j}=0$ for $i=N+2, N+3, \ldots, 2 N-1$

and $j=2 N+1,2 N+2, \ldots, 3 N$

$K_{i j}=0$ for $i=N+1,2 N$ and $j=1,2, \ldots, 3 N$

$K_{i j}=-\frac{1}{2} \frac{\partial}{\partial z}\left(E_{z z} A\right) \frac{\partial v}{\partial z} D_{i-2 N, j}^{(1)}-E_{z z} A \frac{\partial v}{\partial z} D_{i-2 N, j}^{(2)}$

for $i=2 N+2,2 N+3, \ldots, 3 N-1$

and $j=1,2, \ldots, N$

$K_{i j}=0$ for $i=2 N+2,2 N+3, \ldots, 3 N-1$

and $j=N+1, N+2, \ldots, 2 N$

$K_{i i}=-\frac{\partial}{\partial z}\left(E_{z z} A\right) D_{i-2 N, i}^{(1)}-E_{z z} A D_{i-2 N, j}^{(2)}-\rho A \Omega^{2}$

for $i=2 N+2,2 N+3, \ldots, 3 N-1$

$K_{i j}=-\frac{\partial}{\partial z}\left(E_{z z} A\right) D_{i-2 N, j}^{(1)}-E_{z z} A D_{i-2 N, j}^{(2)}$

for $i \neq j, i=2 N+2,2 N+3, \ldots, 3 N-1$

and $j=2 N+1,2 N+2, \ldots, 3 N$ 
Table 1. Natural frequencies of an orthotropic composite beam with $\theta_{f}=15^{\circ}$ and $\theta_{t}=0^{\circ}$

\begin{tabular}{|c|c|c|c|c|c|c|c|c|c|c|c|c|c|}
\hline \multirow[t]{3}{*}{$\bar{\omega}$} & \multicolumn{11}{|c|}{ DQM } & \multirow[t]{3}{*}{ FEM } & \multirow[t]{3}{*}{ Experiment [1] } \\
\hline & \multicolumn{11}{|c|}{ Number of sample points } & & \\
\hline & 7 & 9 & 11 & 13 & 15 & 17 & 19 & 21 & 23 & 25 & 27 & & \\
\hline $\bar{\omega}_{1}$ & 8.5 & 8.2 & 8.2 & 8.2 & 8.2 & 8.2 & 8.2 & 8.2 & 8.2 & 8.2 & 8.2 & 8.5 & 8.2 \\
\hline $\bar{\omega}_{2}^{1}$ & 52.3 & 51.6 & 51.6 & 51.6 & 51.6 & 51.6 & 51.6 & 51.6 & 51.6 & 51.6 & 51.6 & 53.1 & 51.4 \\
\hline
\end{tabular}

Table 2. Natural frequencies of an orthotropic composite beam with $\theta_{f}=30^{\circ}$ and $\theta_{t}=0^{\circ}$

\begin{tabular}{|c|c|c|c|c|c|c|c|c|c|c|c|c|c|}
\hline \multirow[t]{3}{*}{$\bar{\omega}$} & \multicolumn{11}{|c|}{ DQM } & \multirow[t]{3}{*}{ FEM } & \multirow[t]{3}{*}{ Experiment $[1]$} \\
\hline & \multicolumn{11}{|c|}{ Number of sample points } & & \\
\hline & 7 & 9 & 11 & 13 & 15 & 17 & 19 & 21 & 23 & 25 & 27 & & \\
\hline $\bar{\omega}_{1}$ & 5.4 & 5.2 & 5.2 & 5.2 & 5.2 & 5.2 & 5.2 & 5.2 & 5.2 & 5.2 & 5.2 & 5.4 & 5.2 \\
\hline $\bar{\omega}_{2}$ & 33.5 & 33.0 & 33.0 & 33.0 & 33.0 & 33.0 & 33.0 & 33.0 & 33.0 & 33.0 & 33.0 & 34.2 & 33.3 \\
\hline
\end{tabular}

Table 3. Natural frequencies of a tapered and pre-twisted composite beam with $\theta_{f}=15^{\circ}$ and $\theta_{t}=10^{\circ}$

\begin{tabular}{|c|c|c|c|c|c|c|c|c|c|c|c|c|}
\hline \multirow[t]{3}{*}{$\bar{\omega}$} & \multicolumn{11}{|c|}{ DQM } & \multirow[t]{3}{*}{ FEM } \\
\hline & \multicolumn{11}{|c|}{ Number of sample points } & \\
\hline & 7 & 9 & 11 & 13 & 15 & 17 & 19 & 21 & 23 & 25 & 27 & \\
\hline $\bar{\omega}_{1}$ & 9.1 & 9.1 & 9.1 & 9.1 & 9.1 & 9.1 & 9.1 & 9.1 & 9.1 & 9.1 & 9.1 & 8.9 \\
\hline $\bar{\omega}_{2}$ & 55.2 & 55.0 & 55.0 & 55.0 & 55.0 & 55.0 & 55.0 & 55.0 & 55.0 & 55.0 & 55.0 & 53.6 \\
\hline
\end{tabular}

Table 4. Natural frequencies of a tapered and pre-twisted composite beam with $\theta_{f}=20^{\circ}$ and $\theta_{t}=10^{\circ}$

\begin{tabular}{|c|c|c|c|c|c|c|c|c|c|c|c|c|}
\hline \multirow[t]{3}{*}{$\bar{\omega}$} & \multicolumn{11}{|c|}{ DQM } & \multirow[t]{3}{*}{ FEM } \\
\hline & \multicolumn{11}{|c|}{ Number of sample points } & \\
\hline & 7 & 9 & 11 & 13 & 15 & 17 & 19 & 21 & 23 & 25 & 27 & \\
\hline $\bar{\omega}_{1}$ & 7.7 & 7.7 & 7.7 & 7.7 & 7.7 & 7.7 & 7.7 & 7.7 & 7.7 & 7.7 & 7.7 & 7.6 \\
\hline $\bar{\omega}_{2}$ & 46.4 & 46.5 & 46.5 & 46.5 & 46.5 & 46.5 & 46.5 & 46.5 & 46.5 & 46.5 & 46.5 & 46.4 \\
\hline
\end{tabular}

$$
K_{i j}=0 \text { for } i=2 N+1,3 N \text { and } j=1,2, \ldots, 3 N
$$

\section{RESULTS}

The DQM feasibility and accuracy for the composite rotor blades were studied first. The effect of the number of sample points on the solution accuracy was also discussed. As noted in a number of papers [12, $15,26,28]$, the fiber orientation, interphase, aspect ratio, temperature and boundary conditions have effects on the damping of the composite structure. Tables 1 and 2 show the natural frequency of the composite beam with $\theta_{f}=15^{\circ}$ and $\theta_{f}=30^{\circ}$ respectively. Tables 3 , 4 , and 5 show the natural frequency of the tapered and pre-twisted composite beam with $\theta_{f}=15^{\circ}, \theta_{f}=20^{\circ}$ and $\theta_{f}=30^{\circ}$ respectively. The material properties and the geometric dimensions of the composite beam are given as [1]: $G_{12}=2.542 \mathrm{GPa}, E_{11} / G_{12}=3.7, G_{23}=$ $4.305 \mathrm{GPa}, E_{33} / G_{23}=30, G_{13}=5.158 \mathrm{GPa}, v_{31}=0.3, A_{0}$ $=0.4026 \mathrm{~cm}^{2}, I_{0}=0.0034 \mathrm{~cm}^{4}, L=19.05 \mathrm{~cm}$ and $\rho=$ $1550 \frac{\mathrm{kg}}{\mathrm{m}^{3}}$. Different numbers of sample points for each blade, such as 7, 9, 11, 13, 15, 17, 19, 21, 23, 25 and 27, were selected for the convergence analysis. The non-dimensional natural frequencies of the composite blade are defined as $\bar{\omega}_{i}=\omega_{i} \sqrt{\rho A L^{4} / E_{z z} I_{x x}}$. In order 
to assess the accuracy of the DQM model, we computed the natural frequencies and normal modes through the finite element package MARC. The composite blade is modeled by eight-nodded orthotropic plate elements. A three dimensional model with 200 elements are used. The undamped natural frequencies of the similar blade were calculated. Results in Tables 1, 2, 3, 4, and 5 indicated that the natural frequencies calculated using DQM has a better agreement with the experimental data and the FEM results. The results also display that DQM gives quite good accuracy even only 9 sample points are selected. The good agreement between the calculated and the measured natural frequencies of a composite blade indicated that DQM is an accurate and effective method for formulating the dynamic problems of a composite blade. Figures 2, 3, and 4 show the tip response in the $y$ axis direction of the rotor blade with $\Omega$ $=7.7 \mathrm{rad} / \mathrm{sec}, \Omega=15.4 \mathrm{rad} / \mathrm{sec}$ and $\Omega=23.2 \mathrm{rad} / \mathrm{sec}$, respectively. The values of parameters of the composite rotor blade are $E_{z z} I_{x x}=3.99 \times 10^{5} \mathrm{~N} \times \mathrm{m}, G_{x y} J_{z z}$ $=0.4627 \times 10^{5} \mathrm{~N} \times \mathrm{m}, E_{z z} A=2.23 \times 10^{8} \mathrm{~N}, L=9 \mathrm{~m}, r_{0}$ $=0.5 \mathrm{~m}, \rho A=10 \frac{\mathrm{kg}}{\mathrm{m}}$ and $F_{u}=\frac{\left(r_{0}+r\right)}{\left(r_{0}+R\right)} \sin (23.2 t) \frac{\mathrm{N}}{\mathrm{m}}$. The dynamic response of an orthotropic composite rotor

Table 5. Natural frequencies of a tapered and pre-twisted composite beam with $\theta_{f}=30^{\circ}$ and $\theta_{t}=10^{\circ}$

\begin{tabular}{|c|c|c|c|c|c|c|c|c|c|c|c|c|}
\hline \multirow[t]{3}{*}{$\bar{\omega}$} & \multicolumn{11}{|c|}{ DQM } & \multirow[t]{3}{*}{ FEM } \\
\hline & \multicolumn{11}{|c|}{ Number of sample points } & \\
\hline & 7 & 9 & 11 & 13 & 15 & 17 & 19 & 21 & 23 & 25 & 27 & \\
\hline $\bar{\omega}_{1}$ & 5.8 & 5.8 & 5.8 & 5.8 & 5.8 & 5.8 & 5.8 & 5.8 & 5.8 & 5.8 & 5.8 & 5.8 \\
\hline $\bar{\omega}_{2}$ & 35.4 & 35.2 & 35.2 & 35.2 & 35.2 & 35.2 & 35.2 & 35.2 & 35.2 & 35.2 & 35.2 & 34.9 \\
\hline
\end{tabular}

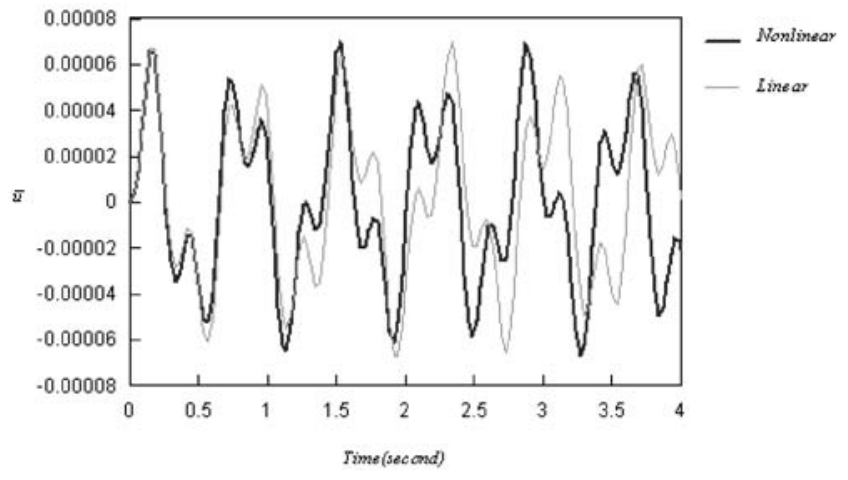

Fig. 2. Tip response in $y$ axis direction of the rotor blade with $\Omega=7.7 \mathrm{rad} / \mathrm{sec}$.

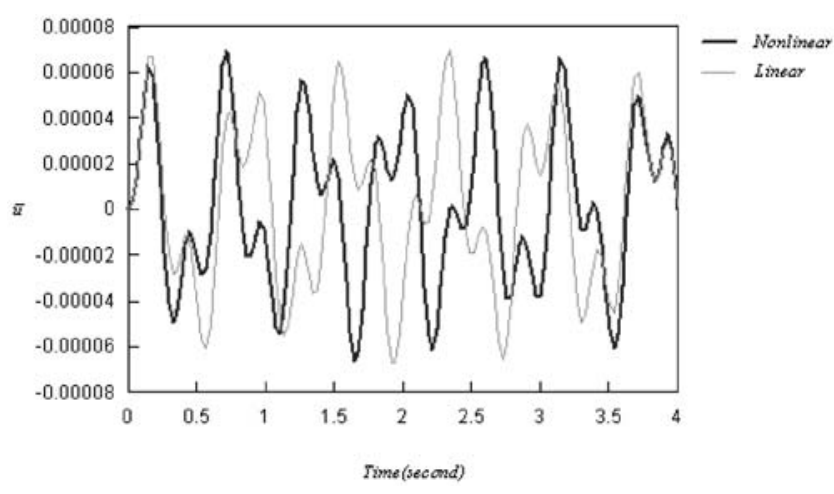

Fig. 3. Tip response in $y$ axis direction of the rotor blade with $\Omega=15.4 \mathrm{rad} / \mathrm{sec}$

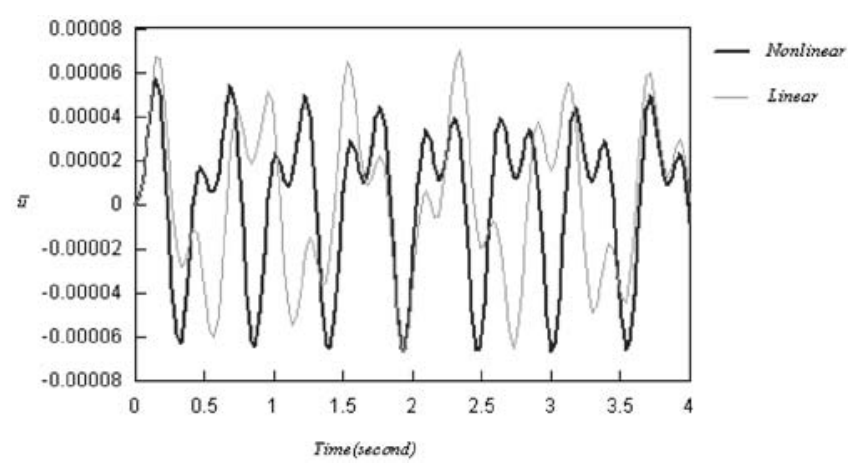

Fig. 4. Tip response in $y$ axis direction of the rotor blade with $\mathbf{\Omega}=\mathbf{2 3 . 2} \mathrm{rad} / \mathrm{sec}$.

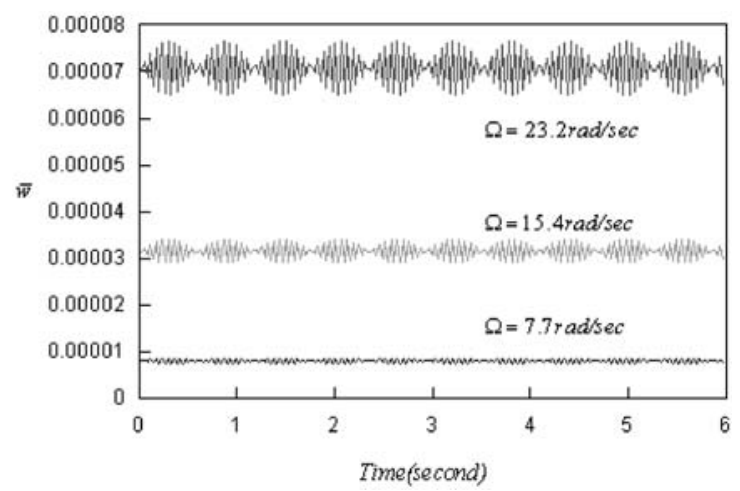

Fig. 5. Tip response in $z$ axis direction of the rotor blade with different $\Omega$. 


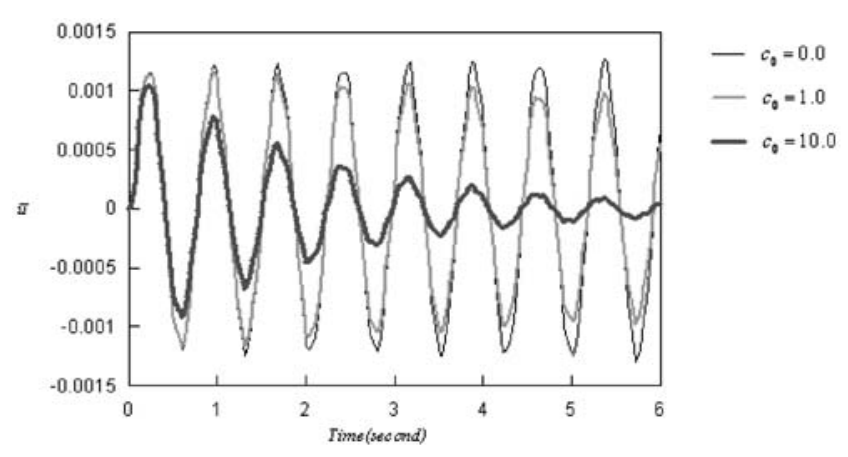

Fig. 6. Tip response in $y$ axis direction of the rotor blade with different $c_{0}$.

blade is simulated for both the nonlinear and linear model. Both linear and nonlinear dynamic responses have been obtained in order to study the significance of the nonlinear effect. The nonlinear terms are set to zero in the simulation of the linear model. It is found that the discrepancies between the nonlinear and linear results are quite significance. Figure 5 shows the tip response in $z$ axis of the rotor blade with $F_{u}=\frac{\left(r_{0}+r\right)}{\left(r_{0}+R\right)} \sin (23.2 t) \frac{\mathrm{N}}{\mathrm{m}}$ and different $\Omega$. The nonlinear vibration analysis of a composite rotor blade has been performed. The nonlinear term is updated for the system during the step-bystep solution. Results in Figure 5 reveal that the deflection at blade tip is dependent upon the rotor blade rotation speed $\Omega$. Results show that higher $\Omega$ were found for the blade with a higher tip displacement. Figure 6 shows the tip response in $y$ axis direction with initial acceleration $1 \frac{\mathrm{m}}{\mathrm{sec}^{2}}$ and different $c_{0}$. The equations of motion are solved by the direct integration method. It can be clearly seen that there is a significant reduction in the vibration by increasing $c_{0}$. Through simulation they show that damping can provide reduction in helicopter rotor blade response. Figure 7 shows the displacement in y axis direction at blade tip with initial acceleration $1 \frac{\mathrm{m}}{\sec ^{2}}$ and different $c_{1}$. The differential equations of the system are discretized by DQM and the nonlinear equations of the system are solved using Newmark method. Results indicate that the internal or the external damping coefficients are the key factors to affect the natural frequencies of a composite blade. It can be clearly seen that there is a significant reduction in the vibration by increasing $c_{1}$. One can see the extensive vibrations without damping.

\section{CONCLUDING REMARKS}

In this work, a DQM formulation on the dynamic

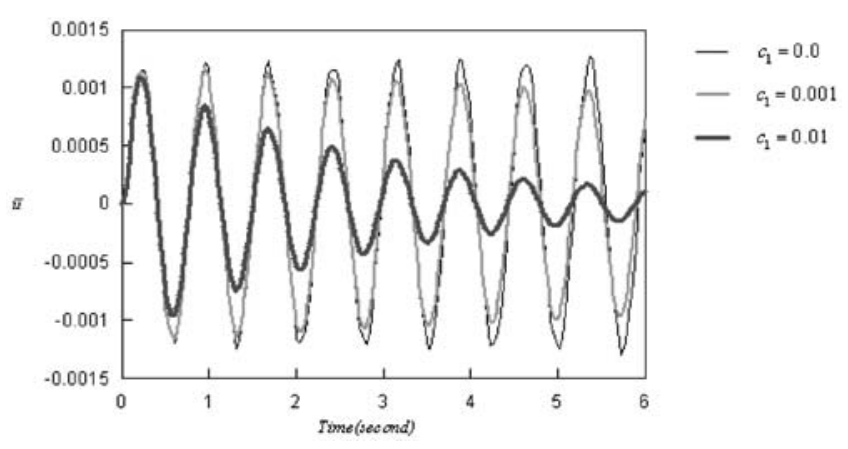

Fig. 7. Tip response in $y$ axis direction of the rotor blade with different $c_{1}$.

problem of an orthotropic composite rotor blade is provided. Results indicate that the DQM is valid for solving such a complicate engineering problem without using a large number of degrees of freedom. This approach is convenient for solving problems governed by the fourth or higher order differential equations. In this approach, only nine sample points are needed to achieve convergence. Due to the coupling effect of torsion, axial displacement and flexure in an orthotropic composite rotor blade, the dynamic characteristics of an orthotropic composite rotor blade are much more complex than the isotropic rotor blade. The internal and external damping effects of the material on the dynamic characteristics of an orthotropic composite rotor blade have also been included. Excellent agreement has been obtained between the calculated and measured results. Numerical results in this work showed that the rotation speed, internal damping and external damping coefficients have a significant influence on the system's dynamic. This work open new areas of application of the DQM.

\section{REFERENCES}

1. Abarcar, R.B. and Cunniff, P.F., "The Vibration of Cantilever Beams of Fiber Reinforced Material," $J$. Compos. Mater., Vol. 6, pp. 504-517 (1972).

2. Bellman, R.E. and Casti, J., "Differential Quadrature and Long-Term Integration," J. Math. Anal. Appl., Vol. 34, pp. 235-238 (1971).

3. Bellman, R.E., Kashef, B.G., and Casti, J., "Differential Quadrature: a Technique for Rapid Solution of Nonlinear Partial Differential Equations," J. Comput. Phys., Vol. 10, pp. 40-52 (1972).

4. Bert, C.W., Jang, S.K., and Striz, A.G., "Two New Approximate Methods for Analyzing Free Vibration of Structural Components," Int. J. Numer. Methods Eng., Vol. 28, pp. 561-577 (1988).

5. Bert, C.W. and Malik, M., "Free Vibration Analysis of 
Tapered Rectangular Plates by Differential Quadrature Method: A Semi-Analytical Approach," J. Sound Vib., Vol. 190, No. 1, pp. 41-63 (1996).

6. Bert, C.W., Wang, X., and Striz, A.G., "Differential Quadrature for Static and Free Vibration Analysis of Anisotropic Plates," Int. J. Solids Struct., Vol. 30, pp. 1737-1744 (1993).

7. Bert, C.W., Wang, X., and Striz, A.G., "Static and Free Vibration Analysis of Beams and Plates by Differential Quadrature Method," Acta Mech., Vol. 102, pp. 11-24 (1994).

8. Bert, C.W., Wang, X., and Striz, A.G., "Convergence of the DQ Method in the Analysis of Anisotropic Plates," $J$. Sound Vib., Vol. 170, pp. 140-144 (1994).

9. Chen, C.L. and Chen, L.W., "Random Vibration and Reliability of a Damped Thick Rotating Blade of Generally Orthotropy Material," Compos. Struct., Vol. 53, pp. 365-377 (2001).

10. Chen, C.L. and Chen, L.W., "Random Response of a Rotating Composite Blade with Flexure-torsion Coupling Effect by the Finite Element Method," Compos. Struct., Vol. 54, pp. 407-415 (2001).

11. Chen, L.W. and Shen, G.S., "Dynamic Stability of Cracked Rotating Beams of General Orthotropy," Compos. Struct., Vol. 37, pp. 165-172 (1997).

12. Coni, M., Benchekchou, B., and White, R.G., "The Structural Damping of Composite Beams with Tapered Boundaries," Compos. Struct., Vol. 35, pp. 207-212 (1996).

13. Crespo Da Silva, M.R.M., "A Comprehensive Analysis of the Dynamics of a Helicopter Rotor Blade," Int. J. Solids Struct., Vol. 35, No. 7-8, pp. 619-635 (1998).

14. Friedmann, P.P., de Terlizzi, M., and Myrtle, T.F., "New Developments in Vibration Reduction with Actively Controlled Trailing Edge Flaps," Math. Comput. Model., Vol. 33, pp. 1055-1083 (2001).

15. Gibson, R.F., "Model Vibration Response Measurements for Characterization of Composite Materials and structures," Compos. Sci. Technol., Vol. 60, pp. 27692780 (2000).

16. Lekhnitskii, S.G., Theory of Elasticity of an Anisotropic Body, Holden-Day, San Francisco (1963).

17. Malik, M. and Bert, C.W., "Implementing Multiple
Boundary Conditions in the DQ Solution of Higherorder PDE Application to Free Vibration of Plates," Int. J. Numer. Methods Eng., Vol. 39, pp. 1237-1258 (1996).

18. Quan, J.R. and Chang, C.T., "New Insights in Solving Distributed System Equations by the Quadrature MethodI. Analysis," Comput. Chem. Eng., Vol. 13, pp. 779-788 (1989).

19. Quan, J.R. and Chang, C.T., "New Insights in Solving Distributed System Equations by the Quadrature MethodII. Numerical Experiments," Comput. Chem. Eng., Vol. 13, pp. 1017-1024 (1989).

20. Rand, O. and Barkai, S.M., "A Refined Nonlinear Analysis of Pre-twisted Composite Blades," Compos. Struct., Vol. 39, No. 1-2, pp. 39-54 (1997).

21. Ruzicka, G.C. and Hodges, D.H., "Application of the Mixed Finite Element Method to Rotor Blade Modal Reduction," Math. Comput. Model., Vol. 33, pp. 11771202 (2001).

22. Schultz, A.B. and Tsai, S.W., "Dynamic Moduli and Damping Ratios in Fiber-reinforced Composites," $J$. Compos. Mater., Vol. 2, No. 3, pp. 368-379 (1968).

23. Shiau, T.N., Yu, Y.D., and Kuo, C.P., "Vibration and Optimum Design of Rotating Laminated Blades," Composites, Vol. 27B, pp. 395-405 (1996).

24. Sivaneri, N.T. and Chopra, I., "Dynamic Stability of a Rotor Blade Using Finite Element Analysis," AIAA J., Vol. 20, No. 5, pp. 716-723 (1982).

25. Thomas, C.R., "Mass Optimization of Non-conservative Cantilever Beams with Internal and External Damping," J. Sound Vib., Vol. 43, No. 3, pp. 483-498 (1975).

26. Vantomme, J., "A Parametric Study of Material Damping in Fiber-reinforced Plastics," Composites, Vol. 26, pp. 147-153 (1995).

27. Wang, Y.R. and Peters, D.A., "The Lifting Rotor Inflow Mode Shapes and Blade Flapping Vibration System Eigen-analysis," Comput. Methods Appl. Mech. Eng., Vol. 134, pp. 91-105 (1996).

28. Yim, J.H. and Gillespie, Jr. J.W., "Damping Characteristics of and AS413501-6 Unidirectional Laminates Including the Transverse Shear Effect," Compos. Struct., Vol. 50, pp. 217-255 (2000). 